\title{
ПОТЕНЦИАЛ ИНТЕЛЛЕКТА
}

\author{
А.В. Маслова
}

\section{МГНОВЕНИЕ ИНТУИЦИИ И АПРИОРНОЕ ЗНАНИЕ}

\begin{abstract}
Аннотация. Проблема определения априорного знания и его наличия во многом похожа на то, что говорится об интуиции. Интуиция рассматривается как изначальный способ получения информации о мире до опыта. Априорное знание и интуииия в данной статье рассматриваются в эволюиионном аспекте, как не статичные и заданные инварианты, а сформированные и изменяющиеся феномены. Задача статьи состоит в том, итобы выявить корреляции в понимании априорного знания и интуиции.
\end{abstract}

Ключевые слова: психология, интуици, а ргіогі, эволюиия, информация, архив, знание, дофамин, инстинкт, интеллект.

\section{Связь мгновения интуици с априорным знанием}

1. Интуиция как способ вычленения

априорного знания.

Загадочное и достоверное "вдруг"

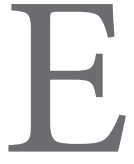

сть такое понятие как предпонимание в герменевтике, своего рода, интерсубъективное пространство смыслов, благодаря чему люди способны понять друг друга, базовые предкоммуникативные смыслы, которые предопределяют то, как человек воспримет то или иное высказывание, слово. Почему люди могут понимать друг друга и, причем понимать то, что было сказано в прошлом, много веков тому назад. Этот вопрос предполагает и другой: как возможно какоелибо знание, которое могло бы быть понято всеми людьми и откуда его источник?

Проблема источника знания ставилась с древнейших времен. Разработка теории эйдосов Платона, самое систематичное учение в этой области, с него можно начинать исторические предпосылки проблемы a priori. Правда, учение Платона подверглось критике Аристотелем, тем самым сформировалось два направления: линия Платона и линия Аристотеля, по второму пути пошла наука, обращаясь к опыту, к эксперименту. Неоплатонизм же вылился в религию, где центральное место занимает Единое. Аристотель же признавал возможность существования эйдосов в человеке в качестве формы, энтелехии, но тогда возникает вопрос: откуда взялась данная форма, гипотеза бога здесь не будет удовлетворительной.

В новом сборнике под названием "Интуиция" философ Кармин определяет проблему интуиции как связанной "с поисками источника знания, истинность которого не подлежит сомнению и не требует никаких доказательств (“самоочевидна")"'. Тем самым, ставится вопрос о самой возможности такого непосредственного способа получения знания, условия и причины такой способности.

Интуитивное знание как знание, которое возможно при нехватке эмпирической информации, и в этом смысле оно должно соотноситься с априорным знанием, возможно, как способ его проявления. Эволюционируя, человек получил новые ментальные способности, но при этом утратил некоторые виды первичного способа познания мира, т.е. "то подсознательное всеведение, которое мы и называем природой... такова была цена, которую человечество заплатило за свою культуру и цивилизацию, за то, чтобы получить специфическую свободу воли"2.

Прояснив механизм появления интуитивного знания, можно приблизиться к пониманию того, что есть априорное знание, потому что интуицией называют то, что как раз предшествует, так называемое пред-знание, пред-чувствие. И в этой связи интуиция выступает как априорная способность наряду с другими способностями, но более древняя. Интуиция первична.

Интуиция как дар предвидения, в смысле предчувствия помогало человеку выжить в условиях опасности на каждом углу, но сейчас, когда страх за свою жизнь не такой тотальный и явный, как раньше, это чувство как и многие другие изрядно притупилось. Правда, остались некоторые племена, наподобие бушменов, известны случаи, когда представитель по-

\footnotetext{
Кармин А.С. Интуиция СПб: Наука, 2011. С. 34.

2 Лоренц К.Л. Кольцо царя Соломона. М., 1970. С.143.
} 


\section{Потенциал интеллекта}

добного племени рассказывал, что он уже чувствует как “у него возникает ощущение, что он тащит на спине тушу антилопы, и по его ногам стекает теплая кровь, собираясь во впадинках под коленками"з, т.е. этот человек не то, что предвидел, а пред-ощутил будущее. Это реликтовое мировосприятие, которое и было утрачено цивилизованным человеком, за ненадобностью, видимо, чем дальше, тем оно все больше нивелируется.

Этот естественный интуитивный способ познания мира сейчас, наоборот, воспринимается как нечто из ряда вон, как сверхспособность. Стоит сказать, что помимо интуиции как предчувствия, есть интуиция ученого, как её можно условно обозначить, потому что она являет собой озарение, некий свет, вспышку в конце напряженного поиска, умственного усилия. Понятие ученого я понимаю в широком смысле, это человек, который занимается мучительным поиском, это может быть музыкант, художник, философ, биолог, потому что критерием “интуиции ученого” является работа с символами, с культурной информацией, со знаками. Возникает тут же вопрос, стоит ли делать жесткую границу между интуицией как предчувствием и интуицией ученого. Здесь, я думаю, нужно определить границы между инстинктом, интеллектом и интуицией. Анри Бергсон утверждал, что интуиция есть высшая стадия инстинктивного поведения: “инстинкт, ставший бескорыстным, осознающим самого себя, способным размышлять о своем предмете и расширять его бесконечно"4. Следовательно, можно интуицию рассматривать как такую способность, которая закреплена в человеческом теле, подобно инстинкту, но которая идет дальше, порождая больше вопросов о своих свойствах.

Один из таких вопросов, это проблема объяснения того, что называют отношением с богом, как с чем-то трансцендентным - как настрой на определенную волну. "Человек улавливает логос, объективный закон мира вещей, когда сливается с объективной действительностью, находится с ней в неразрывном единстве"5. Посредством этого единства возможны такие слова “...я слушаю логос, который “говорит” во мне и через меня"“. Это называется резонанс человека с миром, крайне интересное состояние двух неравновесных структур, и здесь, как мне представляется, можно на-

3 Канетти Э. Масса и власть. М., 1997. С. 364.

4 Бергсон Анри Творческая эволюция М.: Канон-Пресс, 1998. C. 186.

5 Князева Е.Н. Одиссея научного разума М.: ИФ РАН, 1995.

C. 132 .

6 Там же. щупать связь априорного и возникновения нового в момент резонанса.

“Логически организованный опыт в виде причинно-следственной цепочки не может находиться (в отличие от Логоса) “эн архе” - “в начале”: прежде чем начать раскручиваться, логической цепочке надо за что-то зацепиться, а для этого должна существовать какая-то априорная основа. Знание же априорное проистекает из интуиции. В качестве основы для любых рассуждений нужна не логика, а непосредственное чувство"7. Идея единства человека, его сознания с космосом, в материальном смысле, пронизывает всю проблематику априорного знания, подобно искорке в душе, которая есть часть бога в человеке. Этой идеей пронизана вся средневековая мистика, где говорится о способах слияния с богом, которые основаны на интуитивном, а не понятийном.

Через обращение к опыту, непосредственному человеческому опыту, но которого достичь очень сложно, Анри Бергсон утвердил за сознанием способность непосредственно постигать внешнюю реальность. Для него время “уже не априорная форма, а содержание внутреннего чувства, созерцания “я”; это непосредственный факт сознания, постигаемый внутренним опытом"8.

Воспринимать, по Бергсону, более совершенный метод постижения истины и вещей, такими какие они есть, чем постигать их посредством рационального. Произошла замена восприятия понятием, а возникшие на этом разделении философские школы основывались на одном привилегированном восприятии, которое возводится в статус понятия. Бергсон призывает идти не от понятия к восприятию, а от восприятия к понятию. В этом смысле философия понимается не как наука в форме законченной системы, а наоборот как живой, неугомонный творческий процесс, выводящий сознание к пониманию.

Идея непонятийного начала философии наводит меня на мысль, что здесь есть общая точка сближения с буддизмом, где непосредственное постижение и созерцание путем медитации единственно верный способ постичь истину. Достижение непосредственного видения реальности. “”Понимать” - это худший исход, когда нельзя уже воспринимать”. Казалось бы, человек ежемоментно получает опыт, но Бергсон понимает опыт как восприятие, а не синтез рассудка

\footnotetext{
7 Яржембовский С. Успеть до захода // Звезда. 2012. № 2.

8 Блауберг И.И. Анри Бергсон. М.: Прогресс-Традиция, 2003. С. 85.

9 Бергсон А. Восприятие изменчивости // Соч.: в 4 т. СПб,
} 1913-1914. T. 4. C. 7. 


\section{Психология и психотехника 8(47) • 2012}

и чувственности как Кант, у которого, тем самым, исчезает возможность непосредственного опыта, без посредства рассудка, его категориальных (и категорических) тисков. Непосредственный опыт Бергсона это тогда, когда человек говорит, что “то, что я видел, уклоняется от рассудка”10. Опыт по Канту можно описать такими словами: “Стоит мне сказать со всей решимостью: “я видел Бога”, - так сразу то, что я вижу, изменится"11. Есть точка зрения, что непосредственных данных сознания нет, потому что без категорий рассудка нельзя представить жизнь человека, он просто не смог бы выразить бы ни одного осмысленного предложения. В таком случае происходит ограничение опыта, жизни лишь осмысленными предложениями, что я думаю, неправомерно, ведь, таким образом, остается за бортом невыразимое. В этом смысле рассудок - враг интуиции, но непонятным остается насколько жестко стоит разделять эти понятия. Насколько правомерно говорить о непосредственных данностях... их можно отрицать, но сначала надо разобраться, что это и как оно действует. Видным представителем интуитивизма и философом, отстаивающий наличие непосредственных данных сознания, является Анри Бергсон. Он полагал, что интеллект и интуиция неразрывно связаны в процессе познания, поэтому роль интуиции приобрела в его учении статус гносеологической категории.

“Интуиция длительности” - простое уникальное начало, которое пронизывает всю концепцию философа, всю его систему. Интуиция (образ, мысль) вневременна и не имеет определенного места. Анализируя “Этику” Спинозы, можно говорить о его личной интуиции, т.е. чувстве “совпадения между актом, посредством которого наш ум в совершенстве познает истину, и операцией, с помощью которой Бог ее порождает"12. Что поразительно, эта идея может быть некоторым объяснением самой интуиции, не ограничиваясь творчеством Спинозы. Интуиция оказывается в глубине теории, её нужно обнаружить, чтобы понять философа, внять, в чем состояла оригинальность философской системы. Сразу приходит на память блестящая работа И.И. Ильина “Философия Гегеля как учение о конкретности бога и человека", где он пытается понять систему Гегеля посредством вникания в логику его мысли, в то, как она рождалась, для этого как он сам выразился “нужно потерять себя в ней [системе - nрим. M.A.]”.

10 Батай Ж. Внутренний опыт. СПб: Аксиома, 1997. С. 18.

11 Там же.

12 Бергсон Анри. Избранное: Сознание и жизнь. М.: Роспен, 2010. С. 168.
Нужно отречься от своих взглядов, убеждений и отдаться изучаемому предмету, только затем переходить к проведению личного исследования, которое пройдет через душу ученого, но уже обогатившись опытом отречения!

Такой метод можно применить к творчеству каждого мыслителя. Я думаю, такой способ выявления первичной интуиции можно применить не только к философам, но и к ученым, к тем личностям, которые повлияли на развитие какой-либо дисциплины. Эволюционный подход раскрывает смысл преемственности, логического следования от одной системы к другой, одной теории к другой, но что сыграло главную роль, первоначальная интуиция философа (ученого) или предшествующая история, остается под вопросом.

История идей, каким путем она шла, скачкообразно или непрепывно, каждый новый шаг детерминирован предшествующим? “Каждый шаг эволюции создает не просто различие в степени, а различие в сущности"13, - говорит Конрад Лоренц. Это высказывание дает повод к мысли о том, что на каждой ступени эволюции происходит неожиданный резкий скачок, качественно меняющий форму жизни. Можно сказать, что эволюция - это история интуиций, как в культуре, так и на биологическом уровне. Интуиция генетическая, как основа мутаций. Наблюдаемая случайность в генетическом танце, на самом деле, интуитивное решение (выбор, который совершает природа) того, что необходимо добавить или убавить в организме для его успешного существования в мире, т.е. лучшей приспособленности к окружающему миру. Но, конечно, нельзя сказать, что все процессы в природе направлены лишь на лучшую приспособленность, что означает радикальный адаптационизм, что не совсем корректно с точки зрения эволюционной биологии.

К вопросу об априорном знании и интуиции стоит сказать, что недавно обнаружено, что такое существо как желтый слезевик может рационально организовать путь к источнику питания, а это уже работа инстинкта выживания и способности к рациональному поведению ${ }^{14}$. Возможно, и акт интуиции, навевающий мысли о её сверхъестественном происхождении, можно объяснить с помощью эксперимента и свести к работе мозговых клеток.

13 Лоренц К. Оборотная сторона зеркала. М.: Республика, 1998. C. 392.

14 Морозов А. Разум это элементарно // НГ Наука. 2012. № 2012-01-25 [Электронный ресурс] // http://www.ng.ru/ science/2012-01-25/9_intellekt.html. 


\section{Потенциал интеллекта}

\section{Нейрофизиологический ответ}

В связи с необходимостью физического объяснения феномена интуиции, я хотела бы обратиться к научным открытиям в области нейрофизиологии. В этой части работы я буду основываться на книгу Джона Лерера “Как мы принимаем решения". В этой книге изложено физикалистское объяснение феномена интуиции, после прочтения которой, можно прийти к выводу, что интуиция совсем не загадочное, мистическое событие в жизни человека, а всего лишь... колебания дофамина.

Начиная ещё с античности, где Платон определил разум как высшую функцию человека, и предложил метафору колесницы, запряженной лошадьми, которая управляется разумом, чтобы не дать страстям, с которыми философ отождествляет лошадей, овладеть человеком. Образ разума как возничего очень крепко закрепился в западной философской традиции, а, следовательно, и в мировоззрении людей. На протяжении всей истории западной мысли возводились храмы разуму как владыке и удержателя пагубных импульсов, аффектов, эмоций, чувств. Но, ставя таким образом проблему овладения волевыми импульсами, уходит главное, то, что сейчас определяется как эмоциональный интеллект.

Интуицию называют ещё когнитивным чувством, тем, что на границу чувств, эмоций, аффектов, что не просчитано и рациональными решениями, итог которых можно предугадать и рассчитать. Интересно наблюдение того, что во время инсайта человек чувствует уверенность в правильности пришедшего к нему ответа, уверенность в достоверности. Тем самым, очевидна взаимосвязь интуиции как метода открытия истин (hic et nunc в процессе исследования) с чувственностью, эмоциональным. Я думаю, что только это обстоятельство указывает на то, что граница между рациональным и так называемым, иррациональным смазана и довольно условна. Теперь я обращусь непосредственно к последним исследованиям нейрофизиологии, где будет сказано о способностях эмоционального интеллекта.

Заглянув в работу мозга во время выбора, которое определятся как интуитивное, нейрофизиологи обнаружили, что принятие того или иного решения зависит от работы такого вещества как дофамина. “Так же как процесс зрения начинается с сетчатки, процесс принятия решения начинается с колебаний дофамина" ${ }^{\prime 2}$. Тем самым вся загадка интуитивного

15 Лерер Дж. Как мы принимаем решения. М.: Астрель, 2010. C. 62. выбора сводится к связям нейронов, которые усиливаются благодаря активной работе одного нейромедиатора.

Интересно, что как бы не казались нам способы принятия решений иррациональными, основанными на озарении, научные данные показывают, что на самом деле в сознании был тот образ, который направил человека поступить именно так. Стало быть, выбор человек всегда совершает рационально, только иногда это скрыто для самого человека, неосознанно. Только после долгого анализа своего прошлого опыта и исследований мозга можно обнаружить разумность и взвешенность, хоть и сиюминутного, мгновенного, но верного выбора. Это, видимо, и называется интуицией в процессе принятия решения.

"Хаос реальностей превращается в модели взаимозависимостей, позволяющих мозгу предвидеть то, что произойдет дальше"16. В этой связи есть корреляции с синергетическим подходом. Так, предвидение дофамина является аттрактором, который преддетерминирует дальнейший процесс организации, т.е. в самом деле “система строится из будущего"17.

Выявлена сильная связь испытания чувств и принятия решений. “Эмоции являются ключевым элементом процесса принятия решений”'18. Нейрофизиологии удалось даже выяснить определенные отделы мозга, ответственные за генерирование эмоций, это орбитофронтальная кора. Также обнаружено, что только у человека имеются веретенообразные клетки мозга, которые выполняют функции подобно антеннам, они передают эмоции через весь мозг, отсюда присущая интуиции мгновенность.

Нейрофизиологический анализ помогает немного разобраться в процессе интуитивного принятия решения, но пока наука о мозге может только констатировать эффекты и процессы, происходящие в мозгу, его реакцию на определенные стимулы, зависимости состояний от выработки определенных гормонов и других, влияющих на жизненные процессы вещества. Наука говорит, (и пока она ещё только так и может говорить), о том, как это происходит, но не отвечает на вопрос: зачем и собственно что происходит. Возможно, это человеческая амбициозность, искать во всем телеономические связи, ведь такой взгляд на мир характерен человеку и это, можно сказать, его уже наследственная черта, врожденное

16 Там же. С. 63.

17 Князева Е.Н. Одиссея научного разума. М.: ИФ РАН, 1995. C. 109.

18 Лерер Дж. Как мы принимаем решения. М.: Астрель, 2010. С. 37. 


\section{Психология и психотехника 8(47) • 2012}

любопытство, подкрепленное заранее целеполаганием. Если бы можно было все процессы объяснить, сведя их к биологии, то все разговоры о загадочности озарения бы прекратились. Поэтому, переходя к теме о непосредственном озарении, надо сказать, что область эмоции, эмоционального интеллекта содержит в себе часть разгадки природы прозрения, но пока “вдруг” остается наполовину загадкой. На вопрос о возможности мысли, ответить нейрофизиология в полном смысле ещё не может и анализ работы головного мозга в момент принятия решения, интуитивного озарения тоже не раскроет главной проблемы. Ведь, если посмотреть на человека целостно, как на открытую систему, то его структура мозга и его естество конгруэнтны внешнему миру, поэтому связь вроде бы замкнутого тела - мозга - сознания человека с миром, как мне кажется, проявляет себя в наибольшей степени в момент прозрения. "Ведь и всякая природная среда, и среда мозга открыты и нелинейны, а стало быть, являются “полигоном" для разыгрывания процессов самоорганизации"19. Синергетика как раз не удовлетворяется ответом нейрофизиологии, не принимает физикализм, а ищет ответы на границе, на перехлесте разных дисциплин, но находя в них одну и ту же интенцию - поиск первоначала, здесь синергетика делает творческих ход, она пытается свести в единое поле способы решения главной проблемы.

Рассматривая интуицию как способность целостного видения вещей так, как они есть, следует отметить так же, что “дофаминые нейроны автоматически определяют едва различимые схемы, которые мы иначе заметить не можем, они усваивают всю информацию, которую мы не можем осмыслить на сознательном уровне" 20 . В этом проявляется сила эмоционального интеллекта. Припоминание души того знания, которое имеется в ней можно соотнести с работой дофаминовых нейронов. Эти выводы соотносятся с пониманием интуиции как самодостраивания, где "сам поток мыслей и образов в силу своих собственных потенций усложняется и спонтанно выстраивает себя" 21 .

Тайну рождения нового знания можно объяснить, исходя из того, что та интуиция, которая озарила ученого или философа имела собственную историю, зарождаясь в уме человека, и в один момент вышла на

19 Князева Е.Н. Одиссея научного разума. М.: ИФ РАН, 1995. C. 131.

20 Лерер Дж. Как мы принимаем решения. М., 2010. С. 76.

${ }^{21}$ Князева Е.Н., Курдюмов С.П. Интуиция как самодостраивание // Вопросы философии. 1994. № 2. С. 117. уровень сознания, превратившись в образ. Интуиция связана с образным мышлением, с областью ведомства правого полушария, оттого и призывал А. Бергсон к опыту художников и людей творческих профессий, потому что у них восприятие мира углублено, и если философ возьмет на вооружение такой способ движения к истине, то только на этом пути он найдет ответ. Что интересно, этот ответ не имеет четкого определения в том смысле, что нельзя сказать, будет ли он чем- то абсолютно новым или все-таки является следствием изучения предшествующих идей, систем, как синтез того, что уже открыто.

Протяженность есть непосредственная данность сознанию, а не пространство. По Бергсону возможно пространство априори? Нет, протяженность и время как длительность - это интуиции, но можно назвать их априорными? Можно сказать, что эти две интуиции до всякого возможного опыта уже есть в сознании, - вопрос о первоначальных основах познания и жизни человека. Возможно, есть архив знания, благодаря которому происходит продуктивная работа интуиции и собственно прорыв в науке, философии.

Сознание не ограничено мозгом, т.е. телесным очертанием.

Неограниченность этим телом, этим умом, следует из принятия наследственных структур, которые сохраняют информацию предыдущих поколений. Как раз эта информация является конструирующей новый организм, и если это человеческий организм, то эти структуры настраивают весь организм, вплоть до его возможностей как физических так и интеллектуальных. Как сказал Франсис Понж: “Странное тело - человек: его центр тяжести не в нем самом"22. Действительно, человек связан со всем миром как материально, так и духовно, но если у единичного тела можно найти центр тяжести, то говоря о человеке в его целостности, такого центра нет, он вне человека в том смысле, что говоря о неком центре, нужно выйти за пределы себя, определяя самого себя, нужно выти за пределы себя, так же и при определении границ разума, нужно выти за пределы самого разума, чтобы определить эти границы.

Говоря об интуиции, сразу приходит аналогия c “Сотворением Адама” Микеланджело, где Бог как бы почти касается как синапс нейронов, который способствует их связи. Поразительно, что на фреске концы пальцев Бога и Адама не соприкасаются, а

22 Пространство другими глазами французские поэты XX века об образе в искусстве. СПб: изд-во Ивана Лимбаха, 2005. C. 91. 


\section{Потенциал интеллекта}

остается малое пространство, как будто это канал, через который Бог передает человеку дар интуиции. Но, даже опираясь на последние открытия в области нейрофизиологии и психологии, можно убедиться, что загадка окончательно не разгадана, ибо фиксируются факты, например, включения в определенной зоне мозга дофаминового нейрона, но я боюсь сводить такие процессы лишь к физиологии. Образ “Сотворения Адама”, я думаю, являет образ проблемы интуиции. Подобно точке кокоро у японцев, где происходит “соприкосновение с Высшим”. В природе интуиции есть, возможно, то, что уже заложено на генном уровне. Получать новую информацию таким именно инсайтным путем. Возможно, это априорная способность человека познавать мир, которая проявляется только тогда, когда человек готов ею воспользоваться.

Озарения совершаются в сфере бессознательного, если это так, то в каком бессознательном, личном или коллективном? Для меня интереснее вторая версия. В этой связи сразу вспоминается идея об архетипах К.Г. Юнга, которые он определяет как то, что находится в недрах коллективного бессознательного. По словам Августина: “Идеи, которые сами не созданы..., которые содержатся в божественном уме”. В своей работе “Архетип и символ” К.Г. Юнг пишет, что понятие архетипа берет свое начало от платоновского

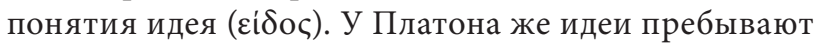
вечно, неизменно, и чтобы их обнаружить, необходимо усилие души, чтобы вспомнить те идеи, которые созерцала душа, находясь вне человеческого тела, т.е. до его рождения. К.Г. Юнг сравнивает идеи Платона с архетипами “изначальными типами, т.е. испокон веку наличными всеобщими образами” 23 . Здесь видна глубокая интуиция Платона, он открыл, что имеются доопытные идеи, но описание их обнаружения, скоpeе, мифично. Но в связи с развитием когнитивных наук, можно теорию идей Платона объяснить с точки зрения современной науки. В диалоге “Менон” излагается способ обнаружения доопытных идей, у Платона они довольно конкретны и причем эти идеи существуют вне человеческого тела, в надлунном мире, но самый интересный момент, это когда душа, навидавши множество истинных сущностей (собственно идей) попадает в человеческое тело, она загадочным образом забывает эти идеи (можно сравнить с вытесненными в бессознательное воспоминаниями) и потом неожиданно их вспоминает. Тогда возникает не менее фундаментальный вопрос: как возникли эйдосы в надлунном мире, и почему душа именно эти

23 Юнг К.Г. Архетип и символ. М.: Ренессанс, 1991. С. 98. идеи созерцает, ведь, так или иначе они соотносятся с вещественным миром. Удивительна способность человека открывать законы природы. Можно снова процитировать Канта, где он говорит об открытии Галилея. Тем самым, можно сказать, что идеи создает сам человек, обладая особой способностью конструирования. Но эта способность не может возникнуть на пустом месте, как бы наивно это не звучало, должна быть определенная программа, которая дает возможность такому конструированию.

Говоря словами Канта, априорное знание необходимо и универсально. Так, например, “число «пи» - один из главных признаков нашей цивилизации и нам подобных. Это пароль разума, подобного нашему. Цивилизация, не знающая «пи», не имеет математики и радиотехники. Она не может сегодня вступить с нами в контакт, да с нею пока что нам, видимо, и не о чем говорить" ${ }^{24}$. Проблема состоит в том, как и почему человек способен узнавать, т.е. открывать такие универсальные величины и законы природы. Что в человеке есть такого, что дает возможность прорыва к познанию всеобщих законов?

В своей работе я попыталась немного прояснить вопрос об условиях получения необходимого и универсального знания. Если рассмотреть гносеологию, то у Платона это концепция припоминания, у Канта это синтез чувственности и рассудка, которые обладают предзаданными априорными структурами, но ни Платон, ни Кант не говорят, откуда возникло доопытное знание, в первом случае - это идеи (эйдосы), во втором априорное знание, формы и категории. Преодоление такого гносеологического подхода производится с помощью эволюционного подхода. Переосмысление проводится в работах Анри Бергсона, где рассматривается человек не как уже готовый в культуре и обладающий набором внутренних детерминант, а в его становлении. В философии Бергсона соединены эволюционизм и интуитивизм как философский метод. Вопрос о возможности прорыва в сферу всеобщего и необходимого, возможно, снимается путем объяснения интуитивного непосредственного способа получения знания при наличии априорных структур, которые направляют и указывают место, где искать нужную информацию. В связи с этим возникает идея накопления, сохранения и передачи информации. Информация не есть знание как таковое, но это то, что лежит в основании всего живого. Поток информации не прекращается, пока происходит жизнь, “жизнь как процесс

24 НГ Наука [Электронный ресурс] // http://www.ng.ru/ science/2011-10-26/10_pi.html. 


\section{Психология и психотехника 8(47) • 2012}

познания”, так называется целая глава в работе К. Лоренца “Оборотная сторона зеркала”, подразумевая под этим возникновение новых структур, которые необходимы для выживания вида. Познание, таким образом, здесь понимается как организованное принятие решения того, каким организм должен быть, чтобы выжить, т.е. лучше приспособиться к новым условиям окружающей среды. Это биологический аспект, можно его назвать информационным, т.к. изменение происходит в гене как носителе жизненного кода, т.е. информации. Загадка в том, как возможен такой сложный и выверенный процесс увеличения генетического разнообразия. Как будто все запрограммировано сохранить как можно больше информации. Ведь если возможна корреляция объема генома человека и томов Британской энциклопедии, то отсюда следует, что генетическая информация может быть прочитана как текст. Мельчайший механизм запоминания геном всего, что происходит с организмов в среде, эволюционно закреплен, но что стало первостимулом к созданию такого универсального способа хранения информации. Возможно, это жизненный порыв, который олицетворяет сверхсознание, может это спонтанность, которую нам так и не удастся постичь. Информация - это то общее, что присуще как развитию жизни, так и развитию культуры, цивилизации. Далее возникает проблема осмысления творческого мышления, гениальности, стремление постичь мгновение озарения, относится к вопросу об априорных возможностях человека, даже не о границах, т.к. говоря о границах, тем самым, нужно быть за пределами этих границ, но, в таком случае, быть не-человеком. Можно сказать, во второй части работы делается переход от биологическо-онтологического аспекта априорного знания к его проявлению в развитии человеческой цивилизации, позволив вольность, можно сказать, в развитии Духа. Если признать сущность Духа, то придется признать и телеологию, которая вытекает из гегелевской теории, но это проблематично, и в тоже время нельзя признать тотальную случайность. Скорее всего, нужно говорить о сложности органи- зации мира, и всех его составляющих частей. В связи со сложной взаимосвязью человека с космосом, ставится проблематика конца, смерти и делается вывод о необходимости создания универсального носителя необходимой для сохранения человеческой цивилизации на том уровне, на каком она подвергнется уничтожению.

Говоря о процессе интуиции, были приведены попытки нейрофизиологов объяснить этот феномен, но такое научное объяснение не проясняет что такое сознание, как возникает мысль. Тем не менее, заслуга такого объяснения состоит в том, что открывает эмоциональную сферу интеллекта, а точнее, говорит об интеллекте как, во многом, об эмоциональном интеллекте.

Таким образом, мною рассмотрены концепции априорного знания и интуитивного прорыва, и я пришла к тому, что интуиция есть априорная функция ума, которая выполняет роль связующего звена между двумя видами информации: генетической, укорененной в природе, что вытекает из факта гомогенности всего живого, и символической, которая производится в сознании как носителе информации, воплощающейся в языке, т.е. в тексте. Последнее есть движущая сила развития цивилизации, подобно как гены есть движущая сила эволюции, а точнее, их мутации. И благодаря нарастанию культурного пространства, которая в связке с развитием генофонда, что позволяет говорить о коэволюции, стала возможна интеллектуальная интуиция, интуиция ученого, философа, она подобна той силе, которая решает на биологическом уровне, что необходимо изменить в организме для его лучшей приспособленности. Можно сказать, что человек, который совершает поворотное открытие, выступает в роли такой решающей силы, ведущей к мутации только не гена, а культуры, тем самым, ведет и к большей приспособленности (появление новых технологий), и восполняет исключительно человеческую потребность в знании..., которая тоже может выводиться из стремления к выживанию, но уже на более сложном уровне.

\section{Список литературь:}

1. Батай Д. Внутренний опыт. СПб: Аксиома, 1997.

2. Бергсон А. Творческая эволюция. М.: КАНОН-пресс, 1998.

3. Бергсон А. Избранное: Сознание и жизнь. М.: Роспэн, 2010.

4. Блауберг И.И. Анри Бергсон. М.: Прогресс-Традиция, 2003.

5. Бескова И.А. Язык символов как эпистемологический феномен // Эволюция, язык, познание. М.: Языки русской культуры, 2000.

6. Кант И. Критика чистого разума // Кант И. Собр. соч. Т. 3. М.: Черо, 1994. 
7. Кармин А.С. Интуиция. СПб: Наука, 2011.

8. Князева Е.Н. Одиссея научного разума. М.: ИФ РАН, 1995.

9. Лерер Дж. Как мы принимаем решения. М.: Астрель, 2010.

10. Лоренц К. Оборотная сторона зеркала М.: Республика, 1998.

11. Лоренц К. Кантовская концепция априори в свете современной биологии. М.: Языки русской культуры, 2000.

12. Марков А. Рождение сложности. М.: Астрель, 2010.

13. Юнг К.Г. Архетип и символ. М.: Ренессанс, 1991.

\section{References (transliteration):}

1. Batay D. Vnutrenniy opyt. SPb: Aksioma, 1997.

2. Bergson A. Tvorcheskaya evolyutsiya. M.: KANON-press, 1998.

3. Bergson A. Izbrannoe: Soznanie i zhizn'. M.: Rospen, 2010.

4. Blauberg I.I. Anri Bergson. M.: Progress-Traditsiya, 2003.

5. Beskova I.A. Yazyk simvolov kak epistemologicheskiy fenomen // Evolyutsiya yazyk poznanie. M.: Yazyki russkoy kul'tury, 2000.

6. Kant I. Kritika chistogo razuma // Kant I. Sobr. soch. T. 3. M.: Chero, 1994.

7. Karmin A.S. Intuitsiya. SPb: Nauka, 2011.

8. Knyazeva E.N. Odisseya nauchnogo razuma. M.: IF RAN, 1995.

9. Lerer Dzh. Kak my prinimaem resheniya. M.: Astrel', 2010.

10. Lorents K. Oborotnaya storona zerkala. M.: Respublika, 1998.

11. Lorents K. Kantovskaya kontseptsiya apriori v svete sovremennoy biologii. M.: Yazyki russkoy kul'tury, 2000.

12. Markov A. Rozhdenie slozhnosti. M.: Astrel', 2010.

13. Yung K.G. Arkhetip i simvol. M.: Renessans, 1991. 